\title{
Characteristics of fall-related injuries attended by an ambulance in Sydney, Australia: a surveillance summary
}

\author{
Susan L. Thomas ${ }^{\mathrm{A}, \mathrm{D}}$, David J. Muscatello ${ }^{\mathrm{B}}$, \\ Paul M. Middleton ${ }^{\mathrm{C}}$ and Wei Zheng ${ }^{\mathrm{B}}$ \\ ${ }^{\mathrm{A}}$ NSW Public Health Officer Training Program, \\ NSW Department of Health \\ ${ }^{\mathrm{B}}$ Centre for Epidemiology and Research, \\ NSW Department of Health \\ ${ }^{\mathrm{C}}$ Ambulance Research Institute, Ambulance Service of NSW \\ ${ }^{\mathrm{D} C o r r e s p o n d i n g ~ a u t h o r . E m a i l: ~ s t h o m @ d o h . h e a l t h . n s w . g o v . a u ~}$
}

\begin{abstract}
In NSW, fall-related injury costs the health system more than any other single cause of injury. A public health surveillance database containing information routinely recorded by the Ambulance Service of NSW was used to define the epidemiology and characteristics of fall-related calls in the Sydney metropolitan area in 2008. The dataset contained 37488 fall-related calls, representing a crude rate of ambulance call-outs for falls of 843 per 100000 population. Females accounted for $57 \%$ of all fall-related calls, and the female rate of injury to the 'hip to foot' region increased with age. Males in all age groups reported 'head and neck' injury most often. In an analysis of a random sample of 1200 calls, $70 \%$ of ambulance dispatches were to a home or residential institution. The findings of this study on the risks for fall-related injury can be used to guide policy for ambulance service delivery. Expansion of data linkage to emergency department and admitted patient databases would provide information to further describe the epidemiology of falls in NSW.
\end{abstract}

Falls account for approximately one-third of all injuryrelated hospitalisations and one-fifth of all fatal injuries ${ }^{1}$ and contribute substantially to the burden on health services in Australia. Each year, one in three older people will experience a fall and will then be at risk of experiencing further falls. ${ }^{2}$ In the period 2003-2004, falls in older Australians that required hospitalisation were estimated to cost $\$ 566$ million. Indirect costs such as lost productivity and costs borne by the patient, family and community were estimated to exceed $\$ 1$ billion annually. ${ }^{1}$

In 2005-2006, the number of new cases of fall injuries in people aged 65 years and over that resulted in hospitalisation was more than 66800 , which represents a $10 \%$ increase since 2003-2004. Age-standardised rates of fall injuries for older people have also risen since 2003-2004, despite screening and prevention programs. ${ }^{3}$

In New South Wales (NSW), fall-related injury costs the health system more than any other single cause of injury. ${ }^{4}$ Falls accounted for $38 \%$ of injury-related hospitalisations in NSW in the period 2004-2005 to 2006-2007. In 2006-2007, there were 43762 hospitalisations and an age-standardised rate of 587 per 100000 population. More than half of those hospitalised were aged over 65 years (a rate of 2747 per 100000 ). In this age group, the rate of hospitalisation was higher for females (3073 per 100000$)$ than males (2275 per 100000$){ }^{4}$

Falls are the second most common reason for emergency ambulance calls in Sydney ${ }^{5}$ however there is limited published information on ambulance call-outs for falls in NSW. We used a public health surveillance database containing information routinely recorded by the Ambulance Service of NSW to describe the epidemiology and characteristics of fall-related ambulance calls in the Sydney metropolitan area in 2008.

\section{Methods}

\section{Data source}

The Ambulance Service of NSW uses Medical Priority Dispatch System $^{\mathrm{TM}}$ (MPDS) software to gather data systematically from 000 callers to prioritise responses. Details of computer-aided ambulance dispatches are recorded in a database at the regional ambulance headquarters. The NSW Department of Health receives hourly updates of these data from the Sydney Ambulance Operations Region, which are used to supplement near-real-time emergency department surveillance of communicable and non-communicable conditions. ${ }^{6}$ 
For this study, we extracted the records of all emergency ambulance calls assigned a problem category of 'fall' in 2008. After 1218 exclusions for cancellations, transfers to other regions, duplicates and hoaxes, we were left with a dataset of 37488 calls for which an ambulance was dispatched. Age and gender were known for $93 \%$ of calls.

The variables used in the analysis were: age, gender, time of call, local government area, call priority (1 or 2), the person's consciousness and breathing status at the time of the call and the description of the location of the patient. The comment text field, which contains a description of the problem by the caller, was also included to permit analysis of the body region of the injury. The time of the call was categorised as 'daytime' (0800-1800 inclusively) or 'out of hours'.

\section{Manual categorisation of a random sample of records}

To categorise the place of the fall and reported injuries sustained, a random sample of 1200 (3.2\%) call records was selected from the complete data set with the SAS RANUNI function. Descriptions of the patients' location and comment texts were reviewed and manually categorised. To be consistent with reports on hospitalisations for falls injuries, ${ }^{3}$ we based our categorisation of place of fall on the external cause of morbidity and mortality rubrics of the International Classification of Diseases, Revision 10, Australian Modification (ICD-10-AM). ${ }^{7}$ We grouped the body locations of injury into 'head and neck', 'hip to foot', 'shoulder to hand', 'trunk/back/ pelvis', 'multiple body regions', 'no injury' or 'unspecified'. 'No injury' was based on comments that the person had no injuries. We also classified whether the call was to request a 'lift only', where assistance was required only for getting up after a fall. Information on the type of fall was missing for approximately $40 \%$ of calls.

Counts from the random sample were scaled to estimate counts for the Sydney region, and confidence intervals for proportions were calculated by exact binomial methods.

\section{Data analysis}

Analysis was performed with SAS statistical software (version 9.2, SAS Institute, Cary, NC, USA). Age-specific

Table 1. Age and gender of patients who had a fall-related ambulance call in the Sydney metropolitan area, 2008

\begin{tabular}{|c|c|c|c|c|c|c|c|c|c|}
\hline \multirow{2}{*}{$\begin{array}{l}\text { Age group } \\
\text { (years) }\end{array}$} & \multicolumn{3}{|c|}{ Male } & \multicolumn{3}{|c|}{ Female } & \multicolumn{3}{|c|}{ Total } \\
\hline & $n$ & $\%$ & $\begin{array}{c}\text { Crude rate per } \\
100000\end{array}$ & $n$ & $\%$ & $\begin{array}{l}\text { Crude rate per } \\
100000\end{array}$ & $n$ & $\%$ & $\begin{array}{l}\text { Crude rate per } \\
100000\end{array}$ \\
\hline $0-4$ & 783 & 2.2 & 543 & 590 & 1.7 & 432 & 1373 & 3.9 & 489 \\
\hline $5-9$ & 473 & 1.4 & 367 & 254 & 0.7 & 207 & 727 & 2.1 & 289 \\
\hline $10-14$ & 547 & 1.6 & 416 & 325 & 0.9 & 259 & 872 & 2.5 & 339 \\
\hline $15-19$ & 390 & 1.1 & 283 & 318 & 0.9 & 241 & 708 & 2.0 & 263 \\
\hline $20-24$ & 413 & 1.2 & 258 & 405 & 1.2 & 257 & 818 & 2.3 & 257 \\
\hline $25-29$ & 412 & 1.2 & 251 & 379 & 1.1 & 229 & 791 & 2.3 & 239 \\
\hline $30-34$ & 419 & 1.2 & 260 & 364 & 1.0 & 221 & 783 & 2.2 & 240 \\
\hline $35-39$ & 442 & 1.3 & 274 & 430 & 1.2 & 261 & 872 & 2.5 & 267 \\
\hline $40-44$ & 521 & 1.5 & 347 & 549 & 1.6 & 361 & 1070 & 3.1 & 354 \\
\hline $45-49$ & 580 & 1.7 & 399 & 519 & 1.5 & 353 & 1099 & 3.2 & 376 \\
\hline $50-54$ & 711 & 2.0 & 554 & 832 & 2.4 & 625 & 1543 & 4.4 & 590 \\
\hline $55-59$ & 608 & 1.7 & 535 & 729 & 2.1 & 623 & 1337 & 3.8 & 580 \\
\hline $60-64$ & 915 & 2.6 & 931 & 986 & 2.8 & 996 & 1901 & 5.5 & 964 \\
\hline $65-69$ & 789 & 2.3 & 1148 & 920 & 2.6 & 1305 & 1709 & 4.9 & 1228 \\
\hline $70-74$ & 1246 & 3.6 & 2347 & 1576 & 4.5 & 2674 & 2822 & 8.1 & 2519 \\
\hline $75-79$ & 1411 & 4.1 & 3382 & 1955 & 5.6 & 3853 & 3366 & 9.7 & 3640 \\
\hline $80-84$ & 1978 & 5.7 & 6435 & 3344 & 9.6 & 7482 & 5322 & 15.3 & 7055 \\
\hline $85+$ & 2477 & 7.1 & 11570 & 5221 & 15.0 & 11542 & 7698 & 22.1 & 11551 \\
\hline \multirow[t]{2}{*}{ Total } & 15115 & $43.4 \%$ & 741 & 19696 & $56.6 \%$ & 943 & 34811 & $100.0 \%$ & 843 \\
\hline & \multicolumn{2}{|c|}{$\begin{array}{c}\text { Age } \\
\text { standardised } \\
\text { rate for males }\end{array}$} & 821 & $\begin{array}{r}A g \\
\text { standa } \\
\text { rate } \\
\text { fem }\end{array}$ & $\begin{array}{l}\text { rdised } \\
\text { for } \\
\text { ales }\end{array}$ & 839 & $\begin{array}{l}\text { A } \\
\text { standa } \\
\text { rate fo } \\
\text { popu }\end{array}$ & $\begin{array}{l}\text { ge } \\
\text { ardised } \\
\text { or total } \\
\text { lation }\end{array}$ & 833 \\
\hline
\end{tabular}

Of a total 37488 calls, 2677 (7.1\%) were excluded from this analysis because of missing age or sex.

Australian standard population Census 2001 used to calculate population rates.

Confidence intervals were not calculated because this analysis used fully enumerated ambulance calls and because of the very large counts. 
rates were calculated from the total age-specific populations of the local government areas included in the Sydney Ambulance Operations region, which includes areas from the Hawkesbury River in the north, to Bowral in the south and Mount Victoria in the west. To compare overall rates in males and females independently of age, direct agestandardised rates were calculated for each gender from the Australian standard population in the 2001 census. $^{8}$

\section{Results}

The crude rate of call-outs for falls was 843 per 100000 population. The lowest rates were for people aged 25-34

Table 2. Estimated incidence of falls by location of patient from a random sample of 1200 fall-related ambulance calls in the Sydney metropolitan area, 2008

\begin{tabular}{lrc}
\hline Location of patient & \multicolumn{1}{c}{$n$} & \% (95\% Cl) \\
\hline Home & 21694 & $58(55-61)$ \\
Residential institution & 4308 & $12(10-13)$ \\
School/public administrative area & 1654 & $4(3-6)$ \\
Sports/athletic area & 312 & $1(0-2)$ \\
Street/highway & 3246 & $9(7-10)$ \\
Trade/service area & 5306 & $14(12-16)$ \\
Industrial/construction area & 125 & $0(0-1)$ \\
Other specified & 593 & $2(1-2)$ \\
Unspecified place & 250 & $1(0-1)$ \\
Total & 37488 & \\
\hline
\end{tabular}

years, with higher rates for children aged under 5 years. The rates increased dramatically from age 50, from around 585 to 11551 per 100000 in people aged 85 years and over (Table 1).

Females accounted for 57\% of fall-related calls, and 25\% of all calls were for women aged 80 years and over. For people aged under 50 years, the rates were generally higher for males, but women over this age had higher rates, until over 85 years when the rates in the two sexes were similar. The crude rates for females were higher than for males ( 943 and 741 per 100 000, respectively). After direct age standardisation, the rates were similar, with 839 and 821 per 100000 for females and males, respectively (Table 1).

Fifty-six percent (21 048) of calls were assigned a priority code 1 , requiring an immediate response. The patient was reported as conscious in 92\% (34601) and breathing in $94 \%$ (35 116) of calls. Sixty percent (22 420) of calls were received during 'daytime hours'.

In the random sample, $58 \%$ ( $95 \%$ confidence interval $(\mathrm{CI})$, 55-61) of ambulance dispatches were to a home, $14 \%$ $(95 \%$ CI, $12-16)$ to a trade or service area and $12 \%(95 \%$ CI, 10-13) to a residential institution (Table 2).

Twenty-nine percent (95\% CI, 26-32) of callers reported 'head and neck' injuries; $20 \%$ (95\% CI, 18-23) reported injuries to the 'hip to foot' region; and 9\% (95\% CI, 7-10)

Table 3. Estimated incidence of injury by body region from a random sample of 1200 fall-related ambulance calls in the Sydney metropolitan area, 2008

\begin{tabular}{llcc}
\hline Body location of injury & & $n$ & $\%(95 \% \mathrm{Cl})$ \\
\hline Head and neck & Head & 10675 & $99(97-100)$ \\
& Neck & 156 & $1(0-3)$ \\
Trunk, back and pelvis & Sub-total & 10831 & $29(26-32)$ \\
& Thorax & 468 & $17(10-26)$ \\
& Abdomen, lower back, lumbar spine and pelvis & 2310 & $83(74-90)$ \\
Shoulder to hand & Sub-total & 2778 & $7(6-9)$ \\
& Shoulder and upper arm & 936 & $30(21-40)$ \\
& Elbow and forearm & 312 & $10(5-17)$ \\
& Wrist and hand & 780 & $25(17-34)$ \\
Hip to foot & Arm unspecified & 1124 & $36(26-46)$ \\
& Sub-total & 3153 & $8(7-10)$ \\
& Hip and thigh & 2247 & $29(24-36)$ \\
Knee and lower leg & 1873 & $22(17-28)$ \\
Unspecified & Ankle and foot & 1498 & $20(15-25)$ \\
Multiple body regions & Leg unspecified & 2029 & $29(23-35)$ \\
\hline
\end{tabular}




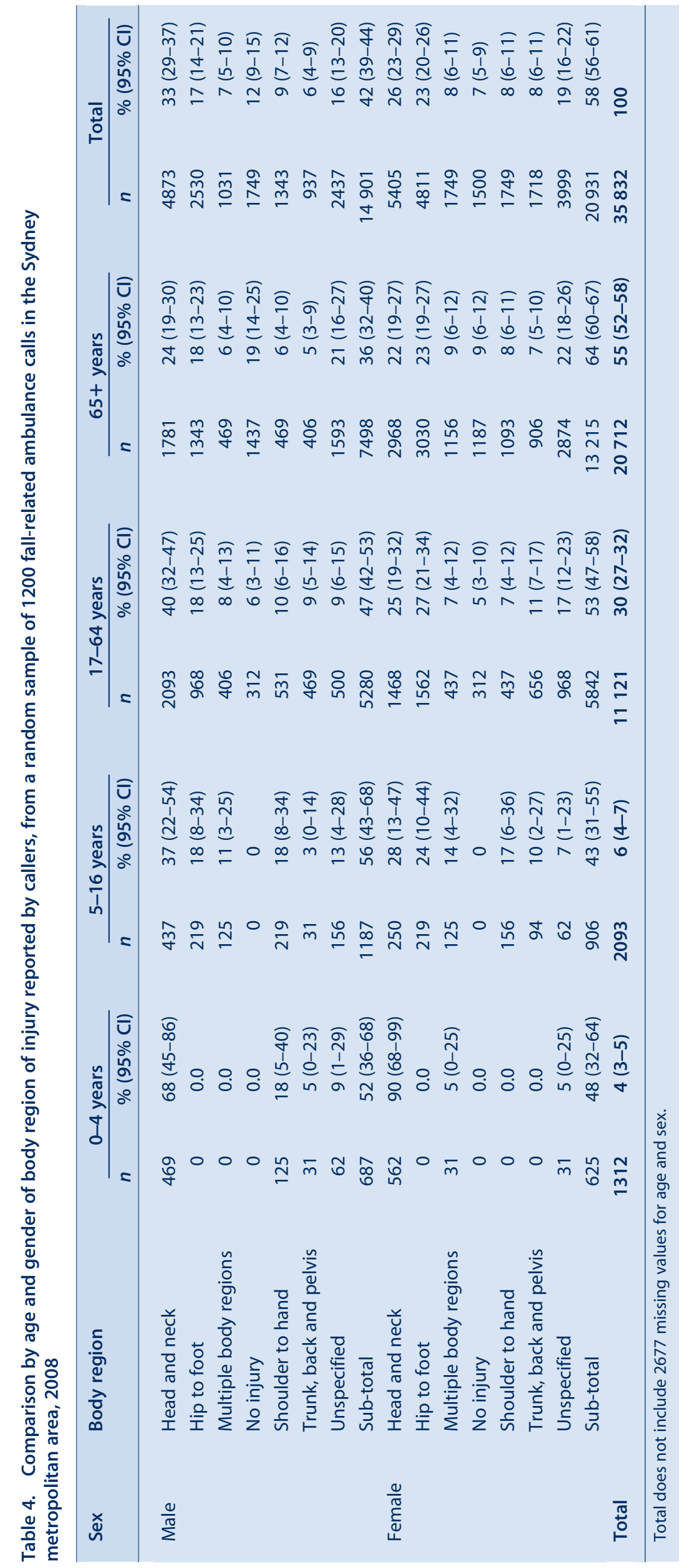


reported 'no injury' (Table 3). Six percent (2247; 95\% CI, 5-7) were calls for a 'lift only'.

For males, calls reporting injuries to the 'head and neck' region dominated all age groups. In females, injuries to the 'hip to foot' region were just as common as injuries to the 'head and neck' region. Among children aged under 5 years, calls for 'head and neck' injuries comprised a far greater proportion than for other age groups, with $68 \%$ (95\% CI, 45-86) of calls for boys and 90\% (95\% CI, 68-99) of those for girls relating to the head or neck (Table 4).

\section{Discussion}

We found a high rate of fall-related ambulance calls in the Sydney region, particularly for the elderly population, which confirms the high burden of falls injury. The rate of fallrelated calls increased from age 50 years onwards. Older women experienced falls requiring an ambulance at a higher rate than men and had higher rates of reported injuries to the 'hip to foot' region. Hip injury or hip fracture may account for many of these injuries, and the greater risk of older women may reflect their higher prevalence of osteoporosis. ${ }^{9}$

The high rate of fall-related ambulance calls for older persons, particularly older women, is consistent with the epidemiology of fall-related hospital admissions in NSW.

Our finding that $70 \%$ of fall-related calls among people of all ages occurred at home or in a residential institution is similar to the national figure of $71 \%$ of falls by older persons requiring hospitalisation taking place in the home or in an aged-care facility. ${ }^{3}$

The high priority assigned to most falls reinforces the fact that falls can be responsible for serious injury and that rapid assistance is often required; nevertheless, many people may experience little or no injury. Some calls were to request a 'lift only'. The use of ambulance services by people who only require assistance to get up warrants further consideration owing to its resource implications.

Ambulance services are well placed to explore a variety of service options related to falls, such as assessment, screening and treatment, and to direct referrals to general practitioners or community health services. Such strategies may meet the needs of patients and prevent unnecessary trips to an emergency department. An ambulance dispatch database could expand the range of information available for public health surveillance of fall-related injuries in the population, and could provide valuable information for guiding the development of a fall-related ambulance service delivery policy.

Once paramedics arrive on the scene, a 'patient health care record' is completed which documents the assessment, findings and treatment. This information is transcribed into a database by Ambulance Service of NSW data coders. These records contain information that could add to the understanding of falls in the community, the response of ambulance services and the overall picture of the burden of falls. Linking these two databases would greatly expand the range of information available to study the characteristics and outcomes of fall injuries. An electronic version of the patient health care record is being developed, which will improve its timeliness. Further linkage to emergency department and admitted patient databases would clearly provide the optimal information for further describing the epidemiology of falls in NSW.

This study has some limitations. The dataset we used had some missing values, perhaps due to the nature of 000 calls, as the callers may be injured, stressed or confused. As a substantial proportion of records lacked information on the circumstance of the fall and whether the patient was transported to hospital, we could not analyse these factors. The time-critical nature of 000 calls may obviate the collection of more detailed information, but consideration should be given to incorporating a simple cause-of-injury classification into call-taking. The lack of information on patient transport may improve with advances in database technology for collecting the information.

\section{Conclusion}

As the population ages and both the number and the agestandardised rate of fall injuries increases, falls and fallrelated injuries will account for an increasing number of ambulance calls. The findings of this study could be used to guide policy for ambulance service delivery.

\section{Acknowledgments}

NSW Public Health Officer Training Program, NSW Department of Health. Scott Deeth, Manager Medical Dispatch Standards, Ambulance Service of NSW. Andrew McNamara, Object Craft Pty Ltd, for assistance in developing the ambulance surveillance database.

\section{References}

1. Australian Institute of Health and Welfare. Australia's health 2008. Cat. No. AUS 99. Canberra: AIHW; 2008.

2. National Ageing Research Unit. Report to the Australian Government Department on Health and Ageing, Injury Prevention Section. An analysis of research on preventing falls and falls injury in older people: Community, residential care and hospital settings (2004 update). Canberra: Commonwealth of Australia; 2004.

3. Bradley C, Pointer S. Hospitalisations due to falls by older people, Australia 2005-2006. Injury research and statistics series number 50. Cat. no. INJCAT 122. Adelaide: AIHW; 2009.

4. Population Health Division, NSW Department of Health. 2008. The health of the people of New South Wales - Report of the Chief Health Officer, Data Book - Injury \& Poisoning. Available from: http://www.health.nsw.gov.au/publichealth/chorep/ databooks/inj_databook.asp (Cited 30 June 2010.) 
5. Bower A, Bendall J, Freitas H, Bawden J. Falls screening and intervention: a new approach by ambulance service NSW extended care paramedics. Poster presentation at the Australia and New Zealand Falls Prevention Society 3rd Australian and New Zealand Falls Prevention Conference, 12-14 October 2008

6. Muscatello DJ, Churches T, Kaldor J, Zheng W, Chiu C, Correll $\mathrm{P}$ et al. An automated, broad-based, near real-time public health surveillance system using presentations to hospital emergency departments in New South Wales. Australia. BMC Public Health 2005; 5: 141. doi:10.1186/1471-2458-5-141

7. National Centre for Classification in Health. The International Statistical Classification of Diseases and Related Health
Problems, 10th revision, Australian modification (ICD-10-AM). Sydney: National Centre for Classification in Health, Faculty of Health Sciences, University of Sydney; 1998.

8. Australian Bureau of Statistics. Australian Demographic Statistics, Dec 2009. Available from: http://www.abs.gov.au/ AUSSTATS/abs@.nsf/mf/3101.0/ (Cited 21 July 2009.)

9. Australian Institute of Health and Welfare. Incidence and prevalence of chronic diseases. Available from: http://www. aihw.gov.au/cdarf/data_pages/incidence_prevalence/ \#Osteoporosis (Cited 30 June 2010.) 